\title{
A Comparative Study Of Smartphone User's Perception And Preference Towards Mobile Payment Methods In The U.S. And Korea
}

Seungjae Shin, Mississippi State University, USA

Won-jun Lee, Cheongju University, South Korea

Dustin Odom, Mississippi State University, USA

\begin{abstract}
As the Smartphone adoption rate increases, Smartphone users pay more attention to mobile payment. There are several options for mobile payment but there is no dominate method. Proximity mobile payment is the newest form of mobile payment. Security, cost, and convenience are three main factors Smartphone users keep in mind when making a mobile payment. This paper investigates Smartphone users' perceptions and preferences toward mobile payment methods in Korea and the U.S. U.S. Smartphone users have a willingness to pay more for a secure mobile payment transaction, even though Korean users have more experience in the mobile payment frequency. Among the three factors, mobile security is the factor of strongest influence on mobile payment frequency in both countries.
\end{abstract}

Keywords: Mobile Payment; Mobile Banking; Mobile Shopping; Mobile P2P; POS Payment

\section{INTRODUCTION}

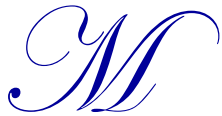

obile payment is payment through mobile phones or mobile devices. Mobile payment is defined by "any transaction on a mobile handset where ownership of money changes hands" (Pope et al., 2011), which can be classified into two forms: remote transactions or proximity-based transactions. Mobile payment is in its early stage and it is cooperated by banks, credit card companies, wireless carriers, and processing companies. It is now starting to catch on in the many developed countries due to the increase in popularity of Smartphones like the iPhone. The Smartphone is a combination of the cellular phone and the personal computer. The adoption of Smartphones has led to the online banking and online shopping consumer to transition into using their Smartphone for these transactions.

In the early 21 st century, mobile banking originated from the SMS text messaging, which was supported by the $2 \mathrm{G}$ mobile technology. SMS mobile banking was a way to make the user's cellular phone a banking tool through text messaging. SMS mobile banking is utilized through two types of messages. One way is through push messages that the bank or financial institution sends to users to inform them about transactions that were performed using the accounts. The second type of message is the pull message where the user initiates the communication with the financial institution in order to receive a one-time password when using mobile banking (Rotimi et al., 2007).

With the advent of $3 \mathrm{G}$ mobile technology, users started to conduct internet banking with their internet enabled mobile devices. As the 3G technology gained popularity, banks and online merchants redesigned their websites to be accessible by mobile devices. This method is very similar as internet banking/internet payment and mobile users use wireless internet access for their payment.

According to the Cellular Telecommunications \& Internet Association's (CTIA) wireless industry statistics (http://www.ctia.org), the number of mobile phone subscribers in the United States is estimated to be over 326.4 million as of December 2013 and wireless penetration rate is $102.2 \%$, indicating the saturation of the U.S. wireless 
market. According to a report by comScore (2014), a leading digital market analysis company, U.S. Smartphone penetration rate was 65\% at the end of 2013. According to the IDC (International Data Corporation) report on the Smartphone market (http://www.idc.com), the U.S. had the largest market share (21.3\%) in 2011.

Korea was one of the leading countries of broadband mobile services in the early 2000s (Yoo, Lyytinen, \& Yang, 2005) and Korea is well known as the world's first mobile service with receiving a TV signal (Shim, Shin, \& Weiss, 2006). According to the Korea Communications Commission (KCC)'s statistics (http://www.kcc.go.kr), as of January 2013, the number of mobile subscribers in Korea is 53.6 million. Based on the 50 million populations, the mobile service penetration rate is expected over 107\%. In addition, the number of Smartphone subscribers is 33.3 million, which means two thirds of the population in Korea has a Smartphone. According to the 2010 survey on the wireless internet usage conducted by Korea Internet and Security Agency (http://www.ksia.or.kr), 18.4\% of Korean mobile users answered that their purpose of using mobile phone internet was economic activities such as mobile banking, mobile ticket, mobile shopping, mobile coupon, and mobile stock. In the age group of $10 \mathrm{~s}$ and $20 \mathrm{~s}$, the payment of product and service goes over $40 \%$.

There has been a new payment method in the last several years, which has been called the mobile wallet, a contactless mobile phone payment. User's mobile phone could be a mobile wallet which includes all financial information like: credit card numbers, bank account numbers, loyalty card numbers, and prepaid card numbers. A real popular example is Google Wallet. The mobile phone acts as a credit card, not by swiping the phone, but by tapping or just approaching credit card reader terminals. Near Field Communications technology like RFID (Radio Frequency Identification) is used in this method. RFID technology allows readers to capture this information simultaneously through Near Field Communication (NFC). VISA PayWave and MasterCard PayPass is a prepaid card with RFID technology. The similar approach is made with a Smartphone and RFID technology. This is due to the high demand for Smartphones and that consumers are always in possession of their mobile devices.

In the first stages of mobile payment adoption, the payment methods have been remote payment methods. What this means is the consumers used their mobile internet connection to access their account from a remote server to pay for the item. Examples of this include mobile banking, mobile shopping, and peer-to-peer payments. In all three of these forms of mobile payment, the user's interface does not have the account information stored on it. Point of Sale (POS) mobile payment is considered to be a proximity payment method. In this payment method, the user's mobile device actually has the account information stored on it in order to perform a more timely transaction by either scanning a barcode/QR code or by using a NFC chip inside the handset.

Due to the popularity of Smartphones, the newest forms of mobile payment are conducted in conjunction with Smartphones. The banking industry also offers an electronic check deposit feature with their account holders. This gives the bank's customers the option to deposit checks by simply taking a picture and texting the picture to the bank. Once the bank receives the message, they will put the amount of the check into to the sender's account without the sender ever leaving the house. Smartphone users can transfer money to a friend or family member's account by just knowing their email address or mobile phone number. Chase Quickpay is a great example of how the finance industry is implementing Smartphone payment for the digital age. Kakao Talk, a number one mobile messenger app in Korea, announced that Kakao Talk provides a mobile payment gateway service to their subscribers from June of 2014 (Gil, 2014). As of now, Kakao Talk allows users to make transactions with their virtual currency through their Bank Wallet Kakao, which also gives users the ability to send coupons or movie tickets to their friends.

In this study, the authors surveyed remote and proximity mobile payment methods and its issues, especially a comparative analysis of mobile payment behaviors in U.S. and Korea. A user survey about mobile payment was conducted to match user perception and preferences for mobile payment methods and authentication methods in both Korea and U.S. At the end of the study there is a regression analysis to test three factors (security, cost, and convenience) as independent variables against mobile payment frequency. 


\section{LITERATURE REVIEW}

\subsection{Studies on Mobile Payments}

There are only a few journal papers about mobile payment because it is a recent phenomenon and in its early stage in the market. There is a comparative study of mobile payment in the United States and some Asian countries (Pope et al., 2011). Herzberg (2003) told that security and convenience are two main motivations for mobile banking. Shin et al. (2009) told that multifactor authentication is a tool against identity-theft in online banking, but neither user had a mind to pay for a fee nor U.S. financial institutes provided it as a free service. Mobile payment methods are sure to be the next standard form of payment, and it will be a practical, convenient, easy-to-use alternative to cash in the near future. One of the problems facing this new push towards a cashless currency is no clear leader in offering this service. It should be cooperation among banking/credit card issuing industry, telecommunications industry, and mobile phone manufacturing industry. Cognet (2010) pointed out that people are waiting to see who takes the lead in providing this service between the finance institutions and the communication companies.

Jang et al. (2009) studied about the e-banking usage between the U.S. and China and found that there are different usage patterns of e-banking between United States and other nations. They showed that the U.S. consumers are more willing to revert to traditional methods of banking than trying new technology. This was due to a low awareness and knowledge of the new technology. However, the factor of security plays an important role in adopting new technologies, especially when dealing with bank accounts.

The number of mobile device users is more than enough to offer a successful market for mobile payment solutions, so why is this method not as common as a credit card, debit card, or cash? There are many theories on why the adoption rate is continuing to lag when the acceptance rate for the Smartphone technology is high. Shin, S. et al. (2009) points out that technology adoption is a factor that needs to be taken into consideration when studying consumers' perceptions of mobile payment services. Kim et al. (2010) shows that personal innovativeness and knowledge on mobile payment are two user centric factors to influence the adoption of mobile payment. They find that compatibility is not a main reason to choose mobile payment. However, Chen (2008) pointed out that the most important factor is compatibility in the consumer's lifestyle. Chen (2008) explained compatibility as the mobile payment complimenting the user's lifestyle and purchasing behaviors, enhancing the buying experience, and also benefiting the consumer's image.

\subsection{Comparative Studies Between Korea and U.S.}

There are several studies about comparative analysis of mobile services between U.S. and Korea. The reason for comparing two countries is while the U.S. was a pioneer in the development of the Internet and ECommerce, Asian countries such as Japan and Korea are leading countries in the mobile service and M-Commerce (Cho, 2008).

Katz and Aakhus (2002) found similar communication habits associated with mobile phone use in Korea and the U.S. regardless of cultural variation. However, Kim (2002) argued that cultural characteristics helped to explain the rapid penetration for the mobile phone services. When introduced in Korea, mobile phone service made a positive social impression such as a symbol of success and a tool of quick information gathering. In the study of Katz, Aakhus, Kim, and Turner (2003), Korean mobile users viewed the mobile phone as more expensive, more stylish and more of a necessity than the U.S. mobile users.

Cho (2008) studied user attitudes and behavior toward M-Commerce in the U.S. and Korea using technology acceptance model. She found that factors such as information, convenience, and entertainment factors significantly affected perceived usefulness and ease of use in both countries, but factors such as price, service, and technology significantly affected users in Korea only. Cho (2009) also studied a cross-cultural analysis of customer attitudes toward mobile phone services in the U.S. and Korea. She revealed the different attitudes affecting mobile phone service in the U.S. and Korea. While functionality, entertainment, and ease of connections were important factors in both countries, convenience was the factor very sensitive to Korean mobile phone users. 
Shin, D. (2009) made a cross-national study of mobile internet services between the U.S. and Korea. He explored the influences of four factors, entertainment, informativeness, interactivity, and availability in the U.S. and Korea. He found that while Korean mobile users considered the most important factor availability; i.e., always on and accessible at all times and places, U.S. users consider entertainment and informativeness more important.

Sung and Mayer (2012) compared Korean and U.S. students responses about the perception of mobile devices and desktop computers. They found that while U.S. students were more sensitive to whether an instructional lesson is presented on mobile devices or desktop computers, Korean students viewed both media as equivalent. They also found that while Korean students rated mobile devices higher, U.S. students rated desktop higher. They concluded that cross-functional differences in both countries might affect their learning.

Kang and Jung (2014) compared the Smartphone needs of U.S. and Korean users using an exploratory factor analysis. They found five basic needs; i.e., physiological, safety, belongingness, self-esteem, and selfactualization and the relationship between these needs and user satisfaction. Belongingness was negatively related to self-actualization in the U.S., which might be interpreted as individual thought and feelings determine behavior more often than does the need to belong. In Korea, self-esteem did not positively affect Smartphone use, because $70 \%$ of Koreans use Smartphones and they consider the Smartphone as a necessity.

\section{DATA COLLECTION METHOD}

The survey is designed to find out several things: (1) mobile user's wireless internet usage pattern, (2) whether mobile users have experienced the four types of mobile payment and willingness to use it, and (3) the preference of suggested authentication methods. Another factor that is studied with this survey is how Smartphone users value cost, convenience, and security for mobile transactions.

The online survey site was opened for two months in 2012. The questionnaire was developed in English and it was translated to Korean. Back translation was used to check whether both surveys were identical. Two universities, one in a metro area and one in a small city, in each country were selected and email invitations were sent to students of those four universities. Student participation was voluntary and anonymous, and the participants were free to post it to their social networking sites such as facebook.com. Participants who did not have a Smartphone or were less than 18 years old were excluded. Because the surveys were open to public by e-mailing and social networking, the authors could not estimate response rate. The percentage of Smartphone users were $85.8 \%, 76.7 \%$ for the U.S. and $93.9 \%$ for Korea. The number of effective survey participants are 283 (U.S.) and 314 (Korea). The Korean survey has a higher percentage of students, 20s, and unemployment because a typical college student in Korea is an unemployed, fulltime student of 20s. Table 1 shows the demographic information about respondents from the two countries.

Table 1: Survey Demographics

\begin{tabular}{|l|c|c|c|c|c|}
\hline & Male & Female & Employed & Student & Age (<30) \\
\hline U.S. & $49.6 \%$ & $50.4 \%$ & $73.6 \%$ & $58.4 \%$ & $44.9 \%$ \\
\hline Korea & $34.4 \%$ & $65.6 \%$ & $19.9 \%$ & $82.3 \%$ & $81.9 \%$ \\
\hline
\end{tabular}

\section{FOUR FORMS OF MOBILE PAYMENT}

According to Fiserv's white paper (2011), there are two categories of mobile payment; Mobile Remote Payment and Mobile Proximity Payment. Mobile Remote Payment can be classified by the following three forms. The first form is bill payments with a mobile device; i.e., mobile banking. The second type of payment is payment to remote retailers and is defined as buying through a retailer's website; i.e., mobile shopping. The third form of mobile payment is between person to person payments; i.e. mobile P2P. This includes paying a friend for an item they are selling, or just allowing a friend to borrow money. PayPal is a well-known service allowing consumers to participate in P2P transactions. Mobile Proximity Payment is classified by mobile POS, which is available by NFC technology or scanning a $\mathrm{QR} / \mathrm{Bar}$ code with a Smartphone. Table 2 summarize the above four types of mobile payment. 
Table 2: The Four Forms of Mobile Payment

\begin{tabular}{|l|l|l|l|l|}
\hline \multirow{2}{*}{} & \multicolumn{3}{|c|}{ Remote Mobile Payment } & \multicolumn{1}{|c|}{$\begin{array}{c}\text { Proximity Mobile } \\
\text { Payment }\end{array}$} \\
\cline { 2 - 5 } & \multicolumn{1}{|c|}{ Mobile Banking } & \multicolumn{1}{|c|}{ Mobile Shopping } & \multicolumn{1}{c|}{ Mobile P2P } & \multicolumn{1}{c|}{ Mobile POS } \\
\hline $\begin{array}{l}\text { Bank Account/Credit } \\
\text { Card Requirement }\end{array}$ & Bank Account & Credit/Debit Card & $\begin{array}{l}\text { Credit/Debit } \\
\text { Card/Bank Account }\end{array}$ & $\begin{array}{l}\text { Credit/Debit } \\
\text { Card/Prepaid Card }\end{array}$ \\
\hline $\begin{array}{l}\text { Smartphone/Internet } \\
\text { Requirement }\end{array}$ & $\begin{array}{l}\text { Smartphone, } \\
\text { mobile banking app, } \\
\text { wireless internet }\end{array}$ & $\begin{array}{l}\text { Smartphone, } \\
\text { online shopping app, } \\
\text { wireless internet }\end{array}$ & $\begin{array}{l}\text { Smartphone, } \\
\text { PayPal app, } \\
\text { wireless internet }\end{array}$ & $\begin{array}{l}\text { NFC enabled } \\
\text { Smartphone, } \\
\text { POS app }\end{array}$ \\
\hline Example & Bank bill payment & $\begin{array}{l}\text { Amazon.com purchasing } \\
\text { through smartphone }\end{array}$ & $\begin{array}{l}\text { PayPal through } \\
\text { smartphone }\end{array}$ & $\begin{array}{l}\text { McDonalds' } \\
\text { contactless mobile } \\
\text { payment }\end{array}$ \\
\hline Service Providers & Banks/Credit Unions & $\begin{array}{l}\text { Online retailers/credit } \\
\text { card company }\end{array}$ & $\begin{array}{l}\text { PayPal, } \\
\text { Clear Xchange }\end{array}$ & $\begin{array}{l}\text { ISIS, Google Wallet, } \\
\text { PayPal Wallet }\end{array}$ \\
\hline
\end{tabular}

Table 3 shows the result from the survey about usage of each mobile payment form in each country. Mobile shopping is the highest in the U.S. due to a lot of consumers taking advantage of the tax break from online retailers like Amazon.com. POS (proximity) payment methods are more common in Korea due to the T-Money being available on Smartphones since 2009. T-Money is a rechargeable pre-paid card used for paying public transportation fares such as subways, buses, and even taxis in Seoul metropolitan area, Korea. Mobile T-money is an integration of Smartphone and T-money. Information about T-money balance is stored on the SIM card and it can be used at 7Eleven convenient store and vending machines (Choe, 2009).

Table 3: Four Forms of Mobile Payment Usage

\begin{tabular}{|l|c|c|c|c|}
\hline & Mobile Banking & Mobile Shopping & Mobile P2P & Mobile POS \\
\hline U.S. & $43.8 \%$ & $56.2 \%$ & $15.7 \%$ & $11.6 \%$ \\
\hline Korea & $47.7 \%$ & $27.2 \%$ & $25.2 \%$ & $28.1 \%$ \\
\hline
\end{tabular}

\section{FACTORS OF MOBILE PAYMENT}

The three factors that seem to be most important to consumers and show up in a lot of the mobile payment studies are security, economic cost, and convenience. Herzberg (2003) told that security and convenience are two main motivations for mobile banking. Jang (2009) found that security and convenience are two variables to explain the adoption of mobile payments. Shin, D. (2009) told that security and convenience along with economical cost are three determinants of the success of online banking. These are also the factors that tend to be on the consumer's mind when deciding about new technological products. In order for new technology to reach substantial adoption in the marketplace, consumers need to feel that the product will be safe to use, easy to use, and within a reasonable price. These three factors will be the focus of this study.

The data collected from the surveys was grouped into different variables that will help to better describe the behavior of mobile internet users. The first variable is Mobile Cost, which is willingness to pay for additional security for mobile internet. The next variable is Mobile Security, which is made up of the responses given to questions about the consumers' usage of security practices for mobile internet. The third variable is Mobile Convenience, which is made up by questions for the value of Mobile Convenience. The last variable is Mobile Payment Frequency, which is a number of mobile payment usages per month.

\subsection{Economic Cost}

Mobile Cost is a variable to gauge consumer's willingness to pay. The question for Mobile Cost is "How much are you willing to pay for additional authentication and secure transactions?" For the simplicity of calculation, the exchange rate between U.S. dollar (USD) and Korea Won (KRW) is assumed 1: 1,000. Table 4 shows the distribution of the two countries' response to this question. 
Table 4: Distribution for Willingness to Pay for Secure Mobile Transaction (Per Month)

\begin{tabular}{|l|c|c|c|c|c|}
\hline & $\mathbf{\$ 0}$ & $\mathbf{\$ 1 - \$ 3}$ & $\mathbf{\$ 4 - \$ 6}$ & $\mathbf{\$ 7}-\mathbf{\$ 9}$ & $\geq \mathbf{\$ 1 0}$ \\
\hline U.S. & $52.1 \%$ & $21.1 \%$ & $17.8 \%$ & $5.8 \%$ & $3.3 \%$ \\
\hline Korea & $57.3 \%$ & $24.8 \%$ & $11.9 \%$ & $4.6 \%$ & $1.3 \%$ \\
\hline
\end{tabular}

\section{$5.2 \quad$ Security}

The next variable is called Mobile Security and is made up of the responses given to questions about the consumers' usage of security practices for mobile internet. The six questions from Table 5 are used to ask Smartphone users about their security usage with mobile transactions. The Mobile Security Index is the number used to measure the Smartphone security experience the users have. It is based on the number of "yes" responses out of the six questions.

Table 5: Questions for the Mobile Security Index

\begin{tabular}{|l|}
\hline 1. Have you ever used a password to lock your Smartphone? \\
\hline 2. Have you ever used a Smartphone with biometric protection? \\
\hline 3. Have you ever used OTP (out-of-band) for your mobile transaction? \\
\hline 4. Have you ever used a pre-determined password for your mobile transaction? \\
\hline 5. Have you ever answered a pre-determined challenge questions for your mobile transaction? \\
\hline 6. Have you ever used an OTP APP for your mobile transaction? \\
\hline
\end{tabular}

For the Mobile Security, the banking industry in Korea provides a digital certificate for the online banking users for free. The personal digital certificate has to be saved on a personal Smartphone or mobile device like a flash drive. Without buying a hardware token, online banking users in Korea are able to use their own Smartphone or flash drive for their authentication at any bank in Korea. In both countries a biometric phone is available. The two most popular forms of biometrics in a Smartphone are fingerprint based and voice recognition based. Table 6 displays the Mobile Security Index distribution in the two countries.

Table 6: Mobile Security Index Distribution

\begin{tabular}{|l|c|c|c|c|c|c|c|}
\hline \multicolumn{1}{|c|}{ Index } & $\mathbf{0}$ & $\mathbf{1}$ & $\mathbf{2}$ & $\mathbf{3}$ & $\mathbf{4}$ & $\mathbf{5}$ & $\mathbf{6}$ \\
\hline U.S. & $5.0 \%$ & $12.8 \%$ & $20.2 \%$ & $31.8 \%$ & $24.0 \%$ & $5.4 \%$ & $0.8 \%$ \\
\hline Korea & $1.0 \%$ & $4.3 \%$ & $15.9 \%$ & $27.5 \%$ & $31.8 \%$ & $17.5 \%$ & $2.0 \%$ \\
\hline
\end{tabular}

\subsection{Convenience}

The last variable assigned is Mobile Convenience. When the internet became popular, online banking became an option for banking customers. One of the benefits of online banking is that account holders do not need to visit the physical location of the bank in order to perform transactions. When mobile payment is available with Smartphones, it is like having a branch of the bank in the hand of customers. Mobile POS payment methods will allow consumers to experience an even faster check out process while shopping. The consumer is able to wave their device by the terminal, and the information will be sent from the consumer's device to the store's terminal without any physical contact between the two. The most notable convenience is the fact the consumer will be able to keep all of their loyalty program cards, gift cards, coupons, bank cards, and credit cards on one mobile device.

Due to convenience of mobile payment being a subjective factor, ten questions about Smartphone's convenience is used as a proxy for Mobile Payment Convenience (Table 7). Smartphones can have multiple functions like a mobile TV, e-reader, handheld navigation, etc. The Mobile Convenience Index is the number used to measure the Smartphone convenience experience the users have. It is based on the number of "yes" responses out of the ten Smartphone activity questions. 
Table 7: Questions for Convenience

\begin{tabular}{|l|}
\hline 1. Have you ever watched online video or TV with your Smartphone? \\
\hline 2. Have you ever done online gaming with Smartphone? \\
\hline 3. Have you ever used SNS (Social Networking Services) with your Smartphone? \\
\hline 4. Have you ever used notification alarms (Reminders) with your Smartphone? \\
\hline 5. Have you ever read a book or magazine on your Smartphone? \\
\hline 6. Have you ever used navigation with your Smartphone? \\
\hline 7. Have you ever checked real-time online information (stocks, sports, auctions) with your Smartphone? \\
\hline 8. Have you ever received or sent e-mail with your Smartphone? \\
\hline 9. Have you ever listened to Internet Radio or MP3 music file on your Smartphone? \\
\hline 10. Do you use your Smartphone instead of watch? \\
\hline
\end{tabular}

Table 8 displays the Mobile Convenience Index distribution in the two countries.

Table 8: Mobile Convenience Index Distribution

\begin{tabular}{|l|c|c|c|c|c|c|c|c|c|c|c|}
\hline Index & $\mathbf{0}$ & $\mathbf{1}$ & $\mathbf{2}$ & $\mathbf{3}$ & $\mathbf{4}$ & $\mathbf{5}$ & $\mathbf{6}$ & $\mathbf{7}$ & $\mathbf{8}$ & $\mathbf{9}$ & $\mathbf{1 0}$ \\
\hline U.S. & $1.2 \%$ & $2.9 \%$ & $7.0 \%$ & $8.7 \%$ & $14.0 \%$ & $11.2 \%$ & $17.4 \%$ & $15.3 \%$ & $14.0 \%$ & $5.8 \%$ & $2.5 \%$ \\
\hline Korea & $.3 \%$ & $0.0 \%$ & $1.3 \%$ & $6.3 \%$ & $9.9 \%$ & $20.2 \%$ & $21.9 \%$ & $23.5 \%$ & $9.9 \%$ & $5.3 \%$ & $1.3 \%$ \\
\hline
\end{tabular}

\subsection{Mobile Payment Frequency}

The question used to assess consumer's Mobile Payment Frequency is, "How many times per month do you perform a mobile payment transaction with your Smartphone?" Table 9 shows the distribution of the two countries' response to this question.

Table 9: Mobile Payment Frequency Distribution

\begin{tabular}{|l|c|c|c|c|c|c|}
\hline \multicolumn{1}{|c|}{ Frequency } & $\mathbf{0}$ & $\mathbf{1 - 5}$ & $\mathbf{6 - 1 0}$ & $\mathbf{1 1 - 1 5}$ & $\mathbf{1 6 - 2 0}$ & $>\mathbf{2 0}$ \\
\hline U.S. & $42.3 \%$ & $37.0 \%$ & $14.1 \%$ & $3.9 \%$ & $1.8 \%$ & $1.1 \%$ \\
\hline Korea & $21.7 \%$ & $25.9 \%$ & $23.3 \%$ & $18.8 \%$ & $8.0 \%$ & $2.2 \%$ \\
\hline
\end{tabular}

Based on Table 9, while $42 \%$ of U.S. Smartphone users never used mobile payment, only $21 \%$ of Korea Smartphone users never used mobile payment. One of the reasons that Korean Smartphone users have a higher Mobile Payment Frequency is Mobile T-Money (Ezell, 2009). From 2007, Korean commuters using public transportation could pay fees with Mobile T-Money. Mobile T-Money can also be transferred between accounts as forms of payment. This is the main reason that Korean Smartphone users show a higher percentage of mobile payment usage experience.

\section{HYPOTHESES}

The purpose of this study is to examine and compare the behavior and perceptions of consumers in the Korean and U.S. mobile payment market. The four hypothesis tested in this study are Mobile Payment Frequency, Mobile Security, Mobile Convenience, and Mobile Cost. The following four are the null hypotheses to be tested in the next section.

$\mathbf{H}_{1}$ : The mean value of Mobile Payment Frequency is the same for Korean and U.S. users.

$\mathbf{H}_{2}$ : The mean value of Mobile Cost is the same for Korean and U.S. users.

$\mathbf{H}_{3}$ : The mean value of Mobile Security is the same for Korean and U.S. users.

$\mathbf{H}_{4}$ : $\quad$ The mean value Mobile Convenience the same for Korean and U.S. users.

\section{RESULTS}

\subsection{ANOVA Tests}

In order to test the level of significance of the mean values of Mobile Frequency, Mobile Cost, Mobile Security, and Mobile Convenience, a one way ANOVA test was conducted. All of the four null hypotheses are 
rejected, which indicates that there is a significant mean difference between the two countries for all of the four variables. The mean values of Mobile Payment Frequency, Mobile Convenience, and Mobile Security in Korea are higher than those in the U.S. with a $1 \%$ significant level. The mean value of Mobile Cost is higher in the U.S. than that in Korea with a 5\% significant level. Table 10 summarizes the output from the four ANOVA test.

Table 10: Results of ANOVA Tests

\begin{tabular}{|l|c|c|c|c|}
\hline Hypothesis & U.S. Mean (SD) & Korea Mean (SD) & F-Statistics & P-Value \\
\hline H1 & $0.89(1.019)$ & $1.72(1.329)$ & 72.485 & $.000^{*}$ \\
\hline H2 & $0.85(1.121)$ & $0.68(.941)$ & 4.129 & $.043^{* *}$ \\
\hline H3 & $2.64(1.350)$ & $3.48(1.190)$ & 65.072 & $.000^{*}$ \\
\hline H4 & $5.42(2.088)$ & $5.97(1.717)$ & 10.706 & $.001^{*}$ \\
\hline
\end{tabular}

\subsection{Regression Analysis}

To find out which factor has a greater influence on Mobile Payment Frequency of each country, the authors made a model with three factors as independent variables and Mobile Payment Frequency as a dependent variable. The following is a basic regression model with four variables.

Mobile Payment Frequency $=\beta_{0}+\beta_{1}$ Mobile Cost $+\beta_{2}$ Mobile Security $+\beta_{3}$ Mobile Convenience $+e$

To compare the three factors' influence on Mobile Payment Frequency between two countries, dummy variables are introduced. The dummy variables are independent variables taking the value either 0 or 1 , which divide survey data into two categories. The dummy variable in a linear regression model is useful to define subsets of observations with different intercepts or slopes without the creation of separate models (Garavaglia \& Sharma, 1998). There are two kinds of dummy variables, an intercept dummy variable and a slope dummy variable. Depending on the value of categorical variable, an intercept dummy variable is assumed to change the intercept term and slope dummy variables can be used when the impact of an independent variable on a dependent variable is assumed to change. In this analysis, country is coded as " 1 " for the U.S. and " 0 " for Korea. Even if there is a higher Mobile Payment Frequency of Korea in the result of ANOVA test, it would be reasonable to assume that the three factors have a different impact on the frequency of mobile payment in each country. Thus, three slope dummy variables are introduced in Equation (1).

Mobile Payment Frequency $=\beta_{0}+\beta_{1}$ Mobile Cost $+\beta_{2}$ Mobile Security $+\beta_{3}$ Mobile Convenience

$+\beta_{4}$ Country*Mobile Cost $+\beta_{5}$ Country*Mobile Security $+\beta_{6}$ Country*Mobile Convenience $+\mathrm{e}$

where Country $=1$ for U.S. Smartphone users, 0 for Korean Smartphone users.

Table 11 represents the output of the regression analysis. The model F-statistics and the corresponding pvalue are 134.4 and 0.000 . The $\mathrm{R}^{2}$ value is 0.5776 . The regression model (2) needs to be tested for the assumption of homoskedasticity. To test the homoskedasticity assumption, the Breusch-Pagan (BP) Test is used. The BP Test is supposed to detect heteroskedasticity by running a regression with the squared residuals as a dependent variable. Because the $p$-value $(2.93 \mathrm{e}-10)$ is less than .01 , the null hypothesis of homoskedasticity was rejected with a $1 \%$ significance level. Therefore, this data was heteroskedastic. The problem with heteroskedasticity is that the tstatistics of coefficients cannot be trusted because the estimated standard errors are biased. The heteroskedasticityconsistent (HC) standard errors procedure was proposed by Halbert White to fit a model with heteroskedastic residual. The output from the HC standard errors has the same coefficient with different $t$-values and $p$-values of the coefficients. The p-values in Table 11 are heteroskedasticity-corrected p-values. The p-values for M-Cost and MSecurity are acceptable within 1\% significance level and the p-value for M-Convenience is acceptable within 5\% significance level. Variance Inflation Factor (VIF) is a measure of multicollinearity, which is caused by highly correlated independent variables. A normal cutoff value is 10.0 and all three independent variables and three terms with slope dummy variables are less than 10 (see Table 12), indicating there is no strong multicollinearity. 
Table 11: Results of Regression

\begin{tabular}{|l|c|c|c|}
\hline \multicolumn{1}{|c|}{ Variable } & Coefficient $\left(\boldsymbol{\beta}_{\boldsymbol{i}}\right)$ & P-Value & $\boldsymbol{\alpha}$ \\
\hline Intercept & -1.187 & 0.000 & $1 \%$ \\
\hline M-Cost & 0.182 & 0.001 & $1 \%$ \\
\hline M-Security & 0.716 & 0.000 & $1 \%$ \\
\hline M-Convenience & 0.055 & 0.014 & $5 \%$ \\
\hline Country*M-Cost & 0.062 & 0.418 & NA \\
\hline Country*M-Security & -0.346 & 0.000 & $1 \%$ \\
\hline Country*M-Convenience & 0.102 & 0.000 & $1 \%$ \\
\hline
\end{tabular}

Table 12: Variable Inflation Factor

\begin{tabular}{|c|c|c|c|c|c|}
\hline M-Cost & M-Security & M-Convenience & $\begin{array}{c}\text { Country* } \\
\text { M-Cost }\end{array}$ & $\begin{array}{c}\text { Country* } \\
\text { M-Security }\end{array}$ & $\begin{array}{c}\text { Country* } \\
\text { M-Convenience }\end{array}$ \\
\hline 2.319 & 1.955 & 1.935 & 3.072 & 4.689 & 5.609 \\
\hline
\end{tabular}

Table 13 summarizes coefficients of each variable in both countries. Because the U.S. is coded as "1" for the dummy variable "Country," U.S. coefficients are sum of coefficients of each variable and its dummy variable term. Comparing the values of the coefficients of the three factors, M-Security is the most influential factor to the Mobile Payment Frequency in both countries. Because the p-value of "Country*M-Cost" is not acceptable with 5\% significance level, we cannot say which country has a higher coefficient for M-Cost.

Table 13: Coefficients for Each Category of U.S. and Korea

\begin{tabular}{|l|c|c|}
\hline & U.S. & Korea \\
\hline M-Cost & $0.244\left(\beta_{1}+\beta_{4}\right)$ & $0.182\left(\beta_{1}\right)$ \\
\hline M-Security & $0.370\left(\beta_{2}+\beta_{5}\right)$ & $0.716\left(\beta_{2}\right)$ \\
\hline M-Convenience & $0.157\left(\beta_{3}+\beta_{6}\right)$ & $0.055\left(\beta_{3}\right)$ \\
\hline
\end{tabular}

\section{DISCUSSION AND CONCLUSION}

With a large usage of Smartphones, mobile users are getting interested in mobile payments. According to comScore's report about U.S. digital future (2014), mobile commerce is predominantly driven by Smartphones and U.S. mobile commerce in 2013 accounts for 7\% of digital commerce. In addition, mobile commerce is increasing with a significantly faster rate. As mobile commerce increases, the mobile payment method will be focused more. There are four types of mobile payments, among which proximity payment is the newest method and is expected to be a potential main mobile payment method in the near future.

In the U.S., introduction of the iPhone and the increase of Smartphone market share have had an impact on mobile payment. However, compared to one of the leading countries for mobile payment (Korea), U.S. adoption rate is relatively slow because both traditional payment companies like credit/debit card companies and consumers of the payment market are satisfied with a current payment systems (Pope et al., 2011). Having a gadget loving culture and a well-developed mobile payment ecosystem plays a crucial role in Korea being a leading country for mobile payments usage (Ezell, 2009).

For the mobile payment behavior and authentication issues, the same surveys were conducted in both the U.S. and Korea. The survey results found that mobile internet with a Smartphone is a part of everyday life in the U.S. and Korea. Among the four mobile payment methods, proximity payment and P2P payment are in their early stage. U.S. has a higher mobile shopping percentage, and Korea has a higher mobile banking percentage.

In the ANOVA analysis, the mean values of Mobile Payment Frequency, Mobile Convenience, and Mobile Security in Korea are higher than those in the U.S. The mean value of Mobile Cost is higher in the U.S. Therefore, U.S. Smartphone users are more willing to pay higher fees for additional security for mobile payments.

A regression analysis is used for finding which factor has a greater effect on Mobile Payment Frequency in each country. For both countries, all of the coefficients of the three factors are of significance. Among the three factors, Mobile Security is the factor of strongest influence on Mobile Payment Frequency in both countries. 
Therefore, in order to increase mobile payment usage by Smartphone users, establishing more secure transaction of mobile payment is the best way in each country.

\section{AUTHOR INFORMATION}

Seungjae Shin received a Ph.D. in information sciences (2003) at the University of Pittsburgh and a Ph.D. in Industrial and Systems Engineering (2013) at Mississippi State University. He is currently an Associate Professor of Information Systems and Supply Chain Management at Mississippi State University, Meridian. His research areas are telecommunications industry analysis and logistics. E-mail: sshin@meridian.msstate.edu (Corresponding author)

Won-jun Lee received a Master degree (1996) and a Ph.D. in Marketing (2005) at the Seoul National University. $\mathrm{He}$ is currently an Associate Professor of Business Management at Cheongju University in South Korea. His research areas are technology marketing, consumer behavior, and e-WOM communication. E-mail: marketing@cju.ac.kr

Dustin Odom received a Master of Business Administration (2011) at Mississippi State University. He is currently a Counselor for the Mississippi State University-Small Business Development Center and also an Adjunct Lecturer of Marketing for Mississippi State University, Meridian. E-mail: dodom@business.msstate.edu

\section{REFERENCES}

1. Chen, L. (2008). A model of consumer acceptance of mobile payment. International Journal of Mobile Communications, 6(1), 32-52.

2. Cho, Y. (2008). Assessing user attitudes toward mobile commerce in the U.S. vs. Korea: Implications for m-commerce CRM. The Journal of Business and Economics Research, 6(2), 91-102.

3. Cho, Y. (2009). A cross-cultural comparison analysis of customer attitudes toward mobile phone services in the U.S. and Korea. International Business \& Economics Research Journal, $h, 8(4), 13-25$.

4. Choe, S. (2009). In South Korea, all of life is mobile. New York Times. Retrieved from http://www.nytimes.com/2009/05/25/technology/25iht-mobile.html

5. Cognet, O. (2010). Who will be the winners or losers in the battle for mobile payment market shares. Journal of Payments Strategy \& Systems, 4(4), 325-333.

6. ComScore. (2014). U.S. digital future in focus 2014. Retrieved from http://www.comscore.com/Insights/ Presentations_and_Whitepapers/2014/2014_US_Digital_Future_in_Focus

7. Darsow, M., \& Listwan, L. (2011). Corporate practitioners moving towards mobile banking: Key factors driving adoption. Journal of Payments Strategy \& Systems, 5(4), 360-372.

8. Ezell, S. (2009). Contactless mobile payment. Retrieved from http://www.itif.org/files/2009-MobilePayments.pdf

9. Fiserv. (2012). Beyond mobile banking: It's time to stake the claim for mobile payments. Retrieved from http://www.fiserv.com/resources/beyond-mobile-banking-claim-for-mobile-payments.htm

10. Garavaglia, S., \& Sharma, A. (1998). A smart guide to dummy variables: Four applications and a macro. Retrieved from http://www.ats.ucla.edu/stat/sas/library/nesug98/p046.pdf

11. Herzberg, A. (2003). Payments and banking with mobile personal devices. Communications of ACM, 46(5), 53-59.

12. Gil, J. (2014). Shopping in Kakao talk...Kakao enters mobile payments market. ETNews. Retrieved from http://english.etnews.com/internet/2933982_1299.html

13. Kang, S., \& Jung, J. (2014). Mobile communication for human needs: A comparison of smartphone use between the U.S. and Korea. Computers in Human Behavior, 35, 376-387.

14. Katz, J. E., \& Aakhus, M. A. (2002). Perpetual contact: Mobile Communication, private talk, public performance. Cambridge: Cambridge University Press.

15. Katz, J. E., Aakhus, M. A., Kim, H. D., \& Turner, M. (2003). Cross-cultural comparison of ICTs'. In L. Fortunati, J. Katz, \& R. Riccini (eds), Mediating the human body: Technology, communication and fashion (pp. 75-86). Mahwah, NJ: Lawrence Erlbaum.

16. Kim, C., Mirusmonov, M., \& Lee, I. (2010). An empirical examination of factors influencing the intention to use mobile payment. Computers in Human Behavior, 26, 310-322. 
17. Kim, S. D. (2002). Korea: Personal meanings. In J. Katz \& M. Aakhus (eds), Perpetual contact: Mobile communication, private talk, public performance (pp. 63-79). Cambridge: Cambridge University Press.

18. OECD. (2011). OECD communications outlook 2011. Retrieved from http://dwmw.files.wordpress.com/ 2011/06/oecd-commoutlook-2011.pdf

19. Pope, M., Pantages, R., Enachescu, N., Dinshaw, R., Joshlin, C., Stone, R., Austria, P. A., \& Seal. (2011). K. mobile payments: The reality on the ground of United States and selected Asian countries. International Journal of Mobile Marketing, 6(2), 88-104.

20. Rotimi, E., Awodele, O., \& Ajayi, O. B. (2007). SMS banking services: A 21st century innovation in banking technology. ISIT Education Conference 2007 Proceedings.

21. Shim, J. P., Shin, S., \& Weiss, M. B. (2006). Digital multimedia broadcasting (DMB): Standards, competition, and regulation in South Korea. Journal of Information Technology Theory And Application, 8(2), 69-81.

22. Shin, D. H. (2009). A cross-national study of mobile internet services: A comparison of U.S. and Korean mobile internet users. Journal of Global Information Management, 17(4), 29-54.

23. Shin, D. H. (2010). Modeling the interaction of users and mobile payment systems: Conceptual framework. International Journal of Human Computer Interaction, 26(10), 917-940.

24. Shin, S., Cunningham, J., Ryoo, J., \& Tucci, J. E. (2009). Authentication and protection for e-finance consumers: The dichotomy of cost versus ease of use. International Journal Electronic Finance, 3(1), 3145 .

25. Sung, E., \& Mayer, R. E. (2012). Student's beliefs about mobile device vs. desktop computers in South Korea and the United States. Computers and Education, 59, 1328-1338.

26. Ulanoff, L. (2011). Google is in your wallet. Retrieved from http://www.pcmag.com/article2/ $0,2817,2385948,00 . \mathrm{asp}$

27. Yoo, Y., Lyytinen, K., \& Yang, H. (2005). The role of standards in innovation and diffusion of broadband mobile services: The case of South Korea. Strategic Information Systems, 14, 323-353. 


\section{NOTES}

